Western University

Scholarship@Western

Neuroepidemiology Research Unit Project

Summaries

Neuroepidemiology Research Unit

2020

Epilepsy risk among survivors of intensive care unit hospitalization for sepsis

Tresah C. Antaya

Britney N. Allen

Lucie Richard

Salimah Z. Shariff

Gustavo Saposnik

See next page for additional authors

Follow this and additional works at: https://ir.lib.uwo.ca/neuruprojectsummaries

Part of the Diagnosis Commons, Epidemiology Commons, Health Services Research Commons, Nervous System Diseases Commons, Neurology Commons, and the Neurosciences Commons 
Authors

Tresah C. Antaya, Britney N. Allen, Lucie Richard, Salimah Z. Shariff, Gustavo Saposnik, and Jorge Burneo 


\section{Epilepsy risk among survivors of intensive care unit hospitalization for sepsis \\ RESEARCH SUMMARY}

\section{KEY FINDINGS}

- $407(0.28 \%)$ patients developed epilepsy within 2 years of their ICU discharge, $103(25.3 \%)$ of whom were exposed to sepsis.

- Sepsis survivors were significantly more likely to develop epilepsy, relative to non-septic ICU survivors.

- Among sepsis survivors, epilepsy risk increased with age and was higher among those with chronic kidney disease.

\section{THE ISSUE}

- Survivors of sepsis, an infection that has spread throughout the body, with brain swelling are at risk of longterm neurological problems, however the risk of epilepsy in this population is unknown.

- The purpose of this study was to determine if patients who survived intensive care unit (ICU) hospitalization with sepsis are at higher epilepsy risk than survivors of ICU hospitalization without sepsis and to identify risk factors for epilepsy among those who had sepsis.

\section{OUR RESEARCH}

- We identified patients discharged between January 1,2010 and December 31, 2015 from an ICU in an Ontario hospital who were previously free of seizures, epilepsy, brain tumours, paraneoplastic syndromes, cancer, strokes, and traumatic brain injuries (Figure 1).

- The exposure group consisted of patients who were hospitalized in an ICU for sepsis. The unexposed group consisted of ICU survivors who did not have sepsis. We followed participants for 2 years after their ICU discharge to identify epilepsy diagnoses.

- We used Cox proportional hazards regression models to estimate epilepsy risk and to identify those sepsis survivors at highest risk.

\section{WHAT WE FOUND}

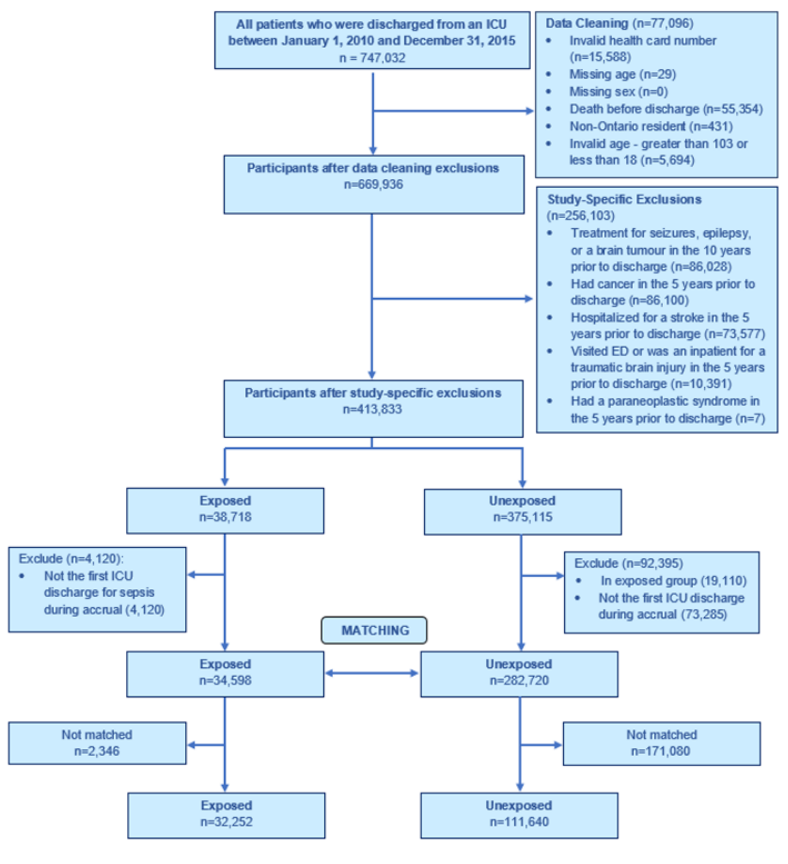

Figure 1. Flow diagram of the study population build.

- We included 143,892 patients, 32,252 (22.4\%) of whom were exposed.

- $407(0.28 \%)$ patients developed epilepsy over follow-up, 103 (25.3\%) of whom were exposed. Sepsis survivors were at significantly higher epilepsy risk.

- In multivariable analysis among the exposed, younger age and having chronic kidney disease significantly increased epilepsy risk.

\section{CONCLUSIONS \& IMPLICATIONS}

- In this study, sepsis significantly increased the long-term risk of epilepsy among the survivors. Younger sepsis survivors and those with chronic kidney disease may be at highest risk. Therefore, sepsis may be a currently-unrecognized risk factor for epilepsy.

\section{For more information, please refer to:}

Antaya et al., Epilepsy risk among survivors of intensive care unit hospitalization for 